\title{
Pendidikan Prakarya dan Kewirausahaan Pada Era Revolusi Industri 4.0
}

\author{
Asri Solihat, Syamsu Yusuf \\ Sekolah Pasca Sarjana Universitas Pendidikan Indonesia \\ Jl. Dr. Setiabudhi No. 229 Bandung \\ asrisolihat@upi.edu
}

\begin{abstract}
The era of education released by the industrial revolution 4.0 is called Education 4.0, which is characterized by digital technology in the learning process known as the cyber system and is able to create a continuous learning process without space and time limits. The challenges of education in the 4.0 industrial revolution era specifically in Indonesia also spoke of competencies that were able to compete with developments. The method used in this study is an explanatory survey with a simple random sampling technique of 130 respondents. The data analysis technique used is simple regression analysis with SPSS 23.0 for Windows. The results show that the exhibition of Education and Entrepreneurship in the Industrial Revolution Era 4.0 fits the good category.
\end{abstract}

Keywords- Education, Crafts, Entrepreneurship, Industrial Revolution 4.0

\begin{abstract}
Abstrak- Era pendidikan yang dipengaruhi oleh revolusi industri 4.0 disebut Pendidikan 4.0 yang bercirikan pemanfaatan teknologi digital dalam proses pembelajaran dikenal dengan sistem siber (cyber sistem) dan mampu membuat proses pembelajaran berlangsung secara kontinu tanpa batas ruang dan tanpa batas waktu. Tantangan pendidikan pada era revolusi industri 4.0 ini khususnya di Indonesia juga berbicara mutu lulusan yang mampu bersaing dengan tuntutan perkembangan. Metode yang digunakan pada penelitian ini adalah explanatory survey dengan teknik simple random sampling sebanyak 130 responden. Teknik analisis data yang digunakan adalah analisis regresi sederhana dengan alat bantu program SPSS 23.0 for Windows. Hasil menunjukkan bahwa gambaran Pendidikan Prakarya dan Kewirausahaan pada Era Revolusi Industri 4.0 berada pada kategori baik.
\end{abstract}

Kata Kunci- Pendidikan, Prakarya, Kewirausahaan, Revolusi Industri 4.0

\section{PENDAHULUAN}

Manusia tidak akan pernah lepas dari pendidikan, baik pendidikan formal maupun informal. Pendidikan merupakan usaha sadar dan terencana, kebutuhan yang sangat penting agar dapat mengarahkan potensi diri menjadi yang lebih baik, agar dapat menyesuaikan diri secara aktif dan dinamis untuk mengahadapi segala perubahan yang terjadi [1][4]. Melalui proses pendidikan, banyak ilmu pengetahuan yang didapatkan untuk diaplikasikan dalam kehidupan sehari-hari, yang dapat meningkatkan aktualisasi diri untuk bekal masa depan manusia[5].

Revolusi industri merupakan perubahan besarbesaran di bidang pertanian, manufaktur, pertambangan, transportasi, teknologi dan memiliki dampak yang mendalam terhadap segala aspek kehidupan dunia. Revolusi industri 1.0 ditandai dengan penggunaan mesin berbasis manufaktur terjadi pada akhir abad ke-18 (pada tahun 1750-1850), revolusi industri 2.0 ditandai dengan produksi massal dengan mesin bertenaga listrik terjadi pada awal abad ke-19, revolusi industri 3.0 ditandai dengan tekonologi informasi dan elektronika guna otomasi produksi terjadi diawal abad ke- 20, dan revolusi industri 4.0 ditandai dengan integrasi online dengan produksi industri untuk peningkatan efisiensi proses industri. Era digital ini bukan hanya berdampak pada bidang industri saja akan tetapi berdampak ke segala aspek kehidupan manusia di dunia tanpa kecuali dunia pendidikan.

Pendidikan kewirausahaan merupakan salah satu bentuk aplikasi kepedulian dunia pendidikan terhadap kemajuan bangsanya, sekarang ini enterpreneurship (kewirausahaan) merupakan mata pelajaran yang dapat diajarkan di sekolah-sekolah dan telah bertumbuh sangat pesat [6], [7]. Pembelajaran prakarya dan kewirausahaan sebagai proses memperoleh kognitif, menstrukturkan pengetahuan merubah makna menjadi pengalaman serta memperoleh keterampilan dan sikap (Kosasih, 2012:5; Rae, 2000). Proses Belajar mengajar prakarya dan kewirausahaan merupakan sebagai rangkaian interaksi antara siswa dengan guru dalam rangka mencapai tujuan [9]. Proses dinamis baik kesadaran, refleksi, asosiasi dan aplikasi yang melibatkan transformasi pengalaman dan pengetahuan kedalam hasil pembelajaran [10]. Mata pelajaran prakarya dan kewirausahaan merupakan mata pelajaran di sekolah yang mempelajari memulai usaha, melatih keterampilan siswa dan memotivasi agar siswa memiliki usaha [11]. 


\section{KAJIAN PUSTAKA}

1) Konsep Pendidikan Kewirausahaan

Pendidikan kewirausahaan merupakan salah satu bentuk aplikasi kepedulian dunia pendidikan terhadap kemajuan bangsanya, sekarang ini enterpreneurship (kewirausahaan) merupakan mata pelajaran yang dapat diajarkan di sekolah-sekolah dan telah bertumbuh sangat pesat (Manimala \& Thomas, 2017; Rodrigues et al., 2015; Witjatno, 2013). Transformasi pengetahuan kewirausahaan telah berkembang pada akhir-akhir ini [12]. Demikian pula di negara kita pengetahuan kewirausahaan diajarkan di sekolah menengah, perguruan tinggi di berbagai kursus bisnis [13]. Pendidikan kewirausahaan merupakan pendidikan yang bertujuan untuk menempa bangsa Indonesia sesuai dengan kepribadian Indonesia yang berdasarkan Pancasila" [14]. Dalam arti yang lebih luas bahwa pendidikan kewirausahaan adalah pertolongan untuk membelajarkan manusia Indonesia sehingga mereka memiliki kekuatan pribadi yang dinamis dan kreatif sesuai dengan kepribadian bangsa Indonesia yang berdasarkan pancasila [12].

Menurut R. Djatmiko Danuhadimedjo adapun perlunya pendidikan kewirausahaan di Indonesia untuk: (1) Untuk mengembangkan, memupuk dan membina bibit atau bakat pengusaha sehingga bibit tersebut lebih berbobot dan selalu mengikuti perkembangan ilmu pengetahuan yang mutakhir. (2) Untuk memberikan kesempatan kepada setiap manusia supaya sedapat mungkin dan menumbuhkan kepribadian wirausaha. (3) Pendidikan kewirausahaan menjadi manusia berwatak dan unggul, memberikan kemampuan untuk membersihkan sikap mental negatif meningkatkan daya saing dan daya juang. 4) Dengan demikian apabila kepribadian wirausaha kita miliki, maka negara kita yang sedang berkembang ini akan dapat menyusul ketinggalan atau menyamai negara yang sudah maju. (5) Untuk menumbuhkan cara berpikir yang rasional dan produktif dalam memanfaatkan waktu dan faktor-faktor modal yang dimiliki oleh wirausaha tradisional pribumi [4], [12].

Pendidikan kewirausahaan berorientasi pada membangun kualitas manusia dari sebelum sampai menjadi pengusaha [15]. Pendidikan kewirausahaan sebuah transformasi pengetahuan kewirausahaan yang di berikan di sekolah-sekolah, kampus dan tempat pendidikan/pelatihan kewirausahaan supaya tahu peran perusahaan, keuntungan dan kekurangan berwirausaha, tahu proses berwirausaha, bisa mengidentifikasi peluang dan berkreativitas, serta tahu dasar-dasar dalam mengelola suatu usaha, diantaranya yaitu pemasaran, keuangan, produksi, organisasi, sumber daya manusia, tantangan masa depan. Sehingga seseorang tahu bagaimana cara mengelola suatu usaha [16]. Ketika seseorang tahu dan mengerti cara mengelola usaha maka mampu mendorong minat seseorang untuk berwirausaha [16].

Pendidikan kewirausahaan sangatlah penting bagi wirausaha, agar mereka tidak meraba-raba dalam melakukan bisnis [17]. Dengan adanya pendidikan maka mereka akan mempertimbangkan semua yang akan mereka lakukan dengan matang. Pendidikan akan membentuk para wirausahawan atau pembisnis yang handal dan tangguh [18]. Siap menghadapi tantangan yang akan mereka hadapi. Besar kecilnya resiko akan dipertimbangkan matang-matang, melakukan segala hal dengan petunjuk yang mereka ketahui tanpa adanya kebimbangan yang tidak pasti. Pendidikan kewirausahaan merupakan salah satu bentuk aplikasi kepedulian dunia pendidikan terhadap kemajuan bangsanya. Di dalam pendidikan kewirausahaan diperlihatkan di antaranya adalah nilai dan bentuk kerja untuk mencapai kesuksesan [17].

2) Konsep Pembelajaran Kewirausahaan

Pembelajaran kewirausahaan berasal dari dua kata, yaitu pembelajaran dan kewirausahaan. Pembelajaran berarti sebuah proses interaksi terhadap suatu peristiwa sehingga terjadi perubahan perilaku sebagai hasil dari belajar. Pembelajaran berasal dari kata belajar yang didefinisikan oleh Siregar \& Nara (2010:5) sebagai suatu aktivitas mental yang berlangsung dalaminteraksi dengan lingkungannya yang menghasilkan perubahan yang bersifat relatih konstan. Pembelajaran sebagai perubahan perilaku yang relatif permanen, terjadi sebagai hasil belajar [20]. Sedangkan kewirausahaan merupakan proses di mana seseorang menggunakan segenap kemampuan dan keterampilan dalam berkreasi dan berinovasi demi menciptakan produk baru untuk kemudian perkenalkan kepada masyarakat guna memperoleh keuntungan [19], [21]. Dengan begitu pembelajaran kewirausahaan merupakan suatu proses perubahan perilaku seseorang dalam melakukan tindakan wirausaha [4], [22].

3) Konsep Proses Belajar Mengajar

Konsep belajar mengajar sebagai suatu proses kegiatan yang terencana dan merupakan perubahan tingkah laku yang meliputi perubahan kecendrungan manusia seperti sikap, minat, atau nilai dan perubahan kemampuannya yakni peningkatan kemampuan untuk melakukan berbagai jenis performance (kinerja) dalam penyelenggaraan setiap jenis dan jenjang pendidikan. Proses belajar mengajar terjadi jika adanya interaksi 
perilaku mengajar pada pihak guru dan perilaku belajar pada pihak siswa tidak berlangsung dalam satu arah melainkan adanya timbal-balik [23].

Proses belajar mengajar terjadi jika adanya interaksi perilaku mengajar pada pihak guru dan perilaku belajar pada pihak siswa tidak berlangsung dalam satu arah melainkan adanya timbal-balik(Hill, Wang, \& Hill, 2018; Iskandar, 2010). Tujuan merupakan titik temu dan bersifat mengikat dan mengarahkan aktifitas kedua belah pihak [26]. Tujuan tersebut dinilai dan dievaluasi agar mengetahui sejauh apa ketercapaian tujuan bersama. Berdasarkan penjelasan tersebut proses belajar mengajar tidak terlepas dari faktor guru dan model pembelajaran yang baik, proses belajar mengajar akan berjalan dengan baik jika guru menggunakan model pembelajaran yang baik juga. Salah satu faktor pendukung keberhasilan dalam bidang pendidikan dipengaruhi oleh cara belajar-mengajar yang dilakukan saat ini[27]-[29].

\section{METODE PENELITIAN}

Metode yang digunakan pada penelitian ini adalah explanatory survey dengan teknik simple random sampling sebanyak 130 responden. Teknik analisis data yang digunakan adalah analisis regresi sederhana dengan alat bantu program SPSS 23.0 for Windows.

\section{1) Hasil}

\section{HASIL DAN PEMBAHASAN}

Berdasarkan pada pengolahan data yang dilakukan memalui penyebaran angket kepada siswa kelas XI SMKN 1 Garut dapat diperoleh hasil mengenai tanggapan responden terhadap dimensi ranah psikomotor dengan perolehan skor tertinggi terdapat pada item pernyataan "Penuturan kata menjadi lebih terlatih karena pelajaran prakarya dan kewirausahaan" dilihat dari perolehan skor sebesar 538 atau $60 \%$. Dengan hasil tersebut dapat dikatakan bahwa responden menjadi terlatih penuturan katanya bearada dalam kategori sedang. Public speaking menjadi terlatih berkat pelajaran prakarya dan kewirausahaan sehingga meningkatkan rasa kepercayaan diri, kemampuan berpikir kritis, dan terlatihnya kemampuan untuk memimpin menjadi lebih baik [4], [30]. Sementara skor pernyataan terendah terdapat pada item pernyataan "Saya tidak berani mengemukakan pendapat karena takut salah" dapat dilihat dari hasil skornya sebesar 497 atau 54\%. Dengan hasil tersebut dapat dikatakan bahwa masih banyak responden masih takut dalam berpendapat yang menjadikan masuk dalam kategori sedang. Menurut Muhhibin Syah (2017) terlalu memikiran sebab-akibat kalau berbicara, dan lebih banyak diam tidak akan membuat orang tersebut lebih unggul dari yang lain. Harus adanya keinginan serta keberanian untuk mengemukakan pendapat, agar lebih percaya diri [31].

Pada hasil dari rata-rata total skor keseluruhan pengambilan data dimensi penampilan berjumlah 8549, dengan demikian persentasi dimensi ranah afektif menurut tanggapan dari 130 responden adalah (8876:14560X100\%) 61\%. Dengan hasil tersebut dapat dikatakan bahwa responden beranggapan bahwa dimensi ranah afektif yang dimiliki cukup. Ranah psikomotor siswa dapat mendukung proses belajar mengajar menjadi lebih aktif karena siswa diarahkan untuk selalu dilibatkan dalam setiap proses belajar sehingga dapat mengarahkan ke arah yang lebih baik [4], [32].

\section{2) Pembahasan}

Era revolusi industri 4.0 merupakan era inovasi disruptif, dimana era ini berkembang sangat begitu pesat, sehingga membawa dampak terciptanya pasar baru bahkan lebih dasyatnya lagi era ini mampu mengganggu atau merusak pasar yang sudah ada, menggantikan teknologi yang sudah ada. Era digital ini bukan hanya berdampak pada bidang industry saja akan tetapi berdampak ke segala aspek kehidupan manusia di dunia tanpa kecuali dunia pendidikan. Era pendidikan yang dipengaruhi oleh revolusi industri 4.0 disebut Pendidikan 4.0 yang bercirikan pemanfaatan teknologi digital dalam proses pembelajaran dikenal dengan sistem siber (cyber sistem) dan mampu membuat proses pembelajaran berlangsung secara kontinu tanpa batas ruang dan tanpa batas waktu. Tantangan pendidikan pada era revolusi industri $4.0 \mathrm{ini}$ khususnya di Indonesia bukan lagi hanya berbicara pada masalah klasik yaitu pemerataan dan pemenuhan akses, sarana prasarana Pendidikan tetapi juga berbicara mutu lulusan yang mampu bersaing dengan tuntutan perkembangan.

Pendidik dituntut untuk bisa beradaptasi dengan zaman, dituntut menguasai lebih duluan teknologoi agar dapat menyesuaikan dengan peserta didik, jangan sampai peserta didik sudah berada pada revolusi industry 3.0 sementara pendidiki masih seputar revolusi industry 2.0 , peserta didik sudah memasuki era digital 4.0 sedangkan guru masih bergelut pada era 3.0 kalau sudah situasi demikian yang terjadi maka dipastikan pincang sehingga titik temu antara guru dengan peserta didik tidak akan ada. Meskipun perkembangan Pendidikan belum bisa secara optimal mengikuti kecepatan akibat revolusi 
industri tersebut tetapi salah satu upaya yang perlu dilakukan untuk menghadapi tantangan revolusi industri 4.0 ini adalah melalui peningkatan kualitas guru agar mampu mengajarkan materi dengan pendekatan penerapan penggunaan Teknologi informasi (TI) dalam proses belajar mengajar pelajaran prakarya dan kewirausahaan, jika tidak maka akan semakin jauh ketinggalan oleh zaman dan ini berefek pada mutu lulusan.

Pada perguruan tinggi, pentingnya pendidikan kewirausahaan diberikan kepada mahasiswa dengan memanfaatkan teknologi digital karena bisa membekali mahasiswa character building enterpreneur 4.0. Berbekal pendidikan kewirausahaan diharapkan pengangguran dari lulusan perguruan tinggi bisa terkurangi. Seperti kita ketahui pengangguran yang terjadi disebabkan orientasi pendidikan yang dilakukan di perguruan tinggi masih tertumpu pada kemampuan penguasaan ilmu pengetahuan dan teknologi saja. Padahal idealnya perguruan tinggi juga harus berorientasi pada paradigma enterpreneur education. Artinya, mengubah pola pikir dari menjadi pekerja ke bagaimana menciptakan lapangan kerjaatau menjadi wirausaha. Sehingga lulusan perguruan tinggi tidak hanya memiliki character building dan employbility skill, tapi juga enterpreneur skill. Oleh karena itu kurikulum pendidikan seharusnya dirancang bertujuan untuk membentuk lulusan agar bisa sukses dalam karier sebagai pekerja maupun sebagai pebisnis atau wirausaha. Dengan demikian tidak ada lulusan perguruan tinggi yang menganggur karena mereka yang terserap ke pasar kerja memiliki kemampuan untuk berwirausaha.

Karakter yang akan dibentuk melalui pendidikan kewirausahaan yaitu cerdas, amanah dan kreatif termasuk di dalamnya upaya peningkatan aspek 5C (creative, cognitive, collaborative, competence, cohesiveness) dan mampu mencetak generasi digitalpreneur. Digitalpreneur merupakan pelaku bisnis yang bergerak dibidang teknologi informasi dan komunikasi. Pendidikan enterpreneur diperlukan mahasiswa dengan mengembangkan kepandaian mereka dalam penggunaan Medsos (Media Sosial) bisa menjadikan sebuah peluang usaha melalui bisnis online. Menggunakan pengetahuan mereka untuk halhal yang positif dan menguntungkan.

\section{KESIMPULAN DAN SARAN}

Revolusi 4.0 memberikan kemudahan untuk mengakses teknologi informasi sehingga semua orang dapat terhubung dengan jejaring sosial. Tantangan bagi sekolah dan perguruan tinggi untuk bisa mencetak lulusannya agar siap menghadapi revolusi tersebut. Langkah yang bisa dilakukan yaitu melalui implementasi pendidikan kewirausahaan dengan memanfaatkan teknologi digital. Hal ini sangat penting karena perkembangan kewirausahaan sudah mengarah pada ekonomi kretif dan digital, setiap bidang ilmu membutuhkan enterpreneur, bisa membangun karakter wirausaha bagi mahasiswa. Intinya dengan membekali pendidikan kewirausahaan berbasis teknologi digital diharapkan bisa membentuk character building enterpreneur.

\section{REFERENSI}

[1] I. Yalcin, F. Calik, and Tutar Omer Faruk, "Research on the Achievement Motivation Levels of the Amateur Football Players," ERPA, vol. 01054, 2017.

[2] U. Tirtarahardja and S. L. La Sulo, Pengantar Pendidikan, Edisi Revi. Jakarta: Rineka Cipta, 2005.

[3] L. Zenner, K. Kumar, and M. Pilz, "Entrepreneurship Education at Indian Industrial Training Institutes - a Case Study of the Prescribed, Adopted and Enacted Curriculum in and around Bangalore Entrepreneurship Education at Indian Industrial Training Institutes - A Case Study of the Prescri," Int. J. Res. Vocat. Educ. Train., vol. 4, no. 1, pp. 69-94, 2017, doi: 10.13152/IJRVET.4.1.4.

[4] M. J. Manimala and P. Thomas, Entrepreneurship Education Experiments with Curriculum, Pedagogy and Target Groups, vol. 49, no. 1. India: Springer, 2017.

[5] A. Hamdani, N.A dan Rhamdani, Manajemen Strategi, Edisi 1. Bandung: Karima, Bandung, 2019.

[6] R. G. Rodrigues, A. Dinis, A. Do Paco, J. Ferreira, and M. Raposo, "The Effect of an Entrepreneurial Training Programme on Entrepreneurial Traits and Intention of Secondary Students," Entrep. Born, Made Educ., vol. 2, no. 15, pp. 77-92, 2015, doi: 10.5772/2649.

[7] S. Witjatno, Pengantar Entrepreneurship. Jakarta.: Grasindo, 2013.

[8] D. Rae, "Understanding Entrepreneurial Learning: A Question of How?," Int. J. Entrep. Behav. Reasearch, vol. 6, no. 3, pp. 145-159, 2000.

[9] Syamsuddin, Psikologi Pendidikan. Bandung: PT Remaja Rosyada, 2005.

[10] D. Rae, Entrepreneurship: from opportunity to action. New York: Palgrave Macmillan, 2007.

[11] S. K. Azizah and S. Kustilah, "Pengaruh Lingkungan Belajar dan Motibasi terhadap 
Prestasi Belajar Kewirausahaan pada Kelas X SMK Puspajati Bulus Kebumen," J. Pendidik., vol. 2, no. 2, 2013.

[12] A. Kusmintarti, N. I. Riwajanti, and A. Asdani, "Pendidikan Kewirausahaan dan Intensi Kewirausahaan dengan Sikap Kewirausahaan sebagai Mediasi," J. Res. Appl. Account. Manag., vol. 2, no. 2, p. 119, 2017, doi: 10.18382/jraam.v2i2.160.

[13] T. J. Bae, S. Qian, C. Miao, and J. O. Fiet, "The Relationship Between Entrepreneurship Education and Entrepreneurial Intentions: A Meta-Analytic Review," Entrep. Theory Pract., vol. 38, no. 2, pp. 217-254, 2014, doi: 10.1111/etap.12095.

[14] B. Alma, Kewirausahaan. Bandung: Alfabeta, 2014.

[15] F. Liñán, J. C. Rodríguez-Cohard, and J. M. Rueda-Cantuche, "Factors affecting entrepreneurial intention levels: A role for education," Int. Entrep. Manag. J., vol. 7, no. 2, pp. 195-218, 2011, doi: 10.1007/s11365-0100154-z

[16] D. Turker and S. S. Selcuk, "Which factors affect entrepreneurial intention of university students?," J. Eur. Ind. Train., vol. 33, no. 2, pp. 142-159, 2009, doi: 10.1108/03090590910939049.

[17] Z. Arasti, M. Kiani Falavarjani, and N. Imanipour, "A Study of Teaching Methods in Entrepreneurship Education for Graduate Students," High. Educ. Stud., vol. 2, no. 1, pp. 210, 2012, doi: 10.5539/hes.v2n1p2.

[18] F. Fischer and F. W. R. L. Z. Sutherland, Grand Challenges in Technology Enhanced Learning Outcomes of the 3rd Alpine Rendez-Vous. Springer, 2014.

[19] E. Siregar and H. Nara, Teori Belajar dan Pembelajaran. Bogor: PT Ghalia Indonesia, 2010.

[20] H. Effendi, "Pengaruh hasil belajar pemasaran online dan hasil belajar kewirausahaan terhadap kinerja penjualan online peserta didik SMK Negeri Surabaya," J. Ekon. Pendidik. dan Kewirausahaan, vol. 5, no. 2, pp. 163-177, 2015.

[21] I. P. Thahara, H. Mulyadi, and D. H. Utama, "EFEKTIVITAS MODEL PROBLEM BASED LEARNING DALAM MENINGKATKAN KEMAMPUAN BERPIKIR KRITIS PESERTA DIDIK PADA KELAS BISNIS DAN," J. Bus. Manag. Educ., vol. 1, no. 2, pp. 70-74, 2016.

[22] Nizar Alam Hamdani, Galih Abdul Fatah Maulani, and Arif Abdullah Muharam, "Entrepreneurial Culture in the Village of the Barbers, Garut, Indonesia," Int. J. Eng. Adv.
Technol., vol. 8, no. 5C, pp. 685-687, Sep. 2019 , doi: 10.35940/ijeat.e1096.0585c19.

[23] B. L. N. Sastradinata, "Model Pembelajaraan Discovery Learning Sebagai Metode untuk Meningkatkan Prestasi Belajar," Jurmal Pendidik. Manaj. Bisnis, vol. 11, pp. 35-54, 2016.

[24] L. M. Hill, D. Wang, and L. M. Hill, "Integrating sustainability learning outcomes into a university curriculum A case study of institutional dynamics," 2018, doi: 10.1108/IJSHE-06-20170087.

[25] Iskandar, Psikologi Pendidikan. Jakarta: Gaung Persada Press, 2010.

[26] E. Suprapto, "Pengaruh Model Pembelajaran Kontekstual, Pembelajaran Langsung dan Motivasi Berprestasi Terhadap Hasil Belajar Kognitif," INVOTEC, vol. XI, no. 1, pp. 23-40, 2015.

[27] A. Karaseva, P. Pruulmann-vengerfeldt, and A. Siibak, "Relationships between in-service teacher achievement motivation and use of educational technology : case study with Latvian and Estonian teachers," Technol. Pedagog. Educ., vol. 5139, no. June, pp. 1-15, 2017, doi: 10.1080/1475939X.2017.1339633.

[28] F. Muhammad and A. Akbar, "PRAKARYA DAN KEWIRAUSAHAAN MELALUI PEMBELAJARAN SNOWBALL," 2010.

[29] N. A. Hamdani and A. Ramdhani, Teori Organisasi. Garut: Karima, Bandung, 2019.

[30] M. Shakroum, K. W. Wong, and C. C. Fung, "The Influence of Gesture-based Learning System (GBLS) on Learning Outcomes," Comput. Educ., pp. 1-46, 2017, doi: 10.1016/j.compedu.2017.10.002.

[31] M. F. Lamar, J. A. Wilhelm, M. Cole, M. F. Lamar, J. A. Wilhelm, and M. C. A, "A mixed methods comparison of teachers' lunar modeling lesson implementation and student learning outcomes," J. Educ. Res., vol. 0, no. 0, pp. 1-16, 2016, doi: 10.1080/00220671.2016.1220356.

[32] M. Syah, Psikologi Pendidikan dengan Pendekatan Baru (Revisi). Bandung: Remaja Rosada Karya, 2017. 